\title{
Meeting the Challenge to Improve the Treatment of Hypertension in Blacks
}

\author{
Antonio Alberto Lopes, MD, PhD;1 Sherman A. James, PhD;2 Friedrich K. Port, MD, MS; ${ }^{3}$ \\ Akinlolu O. Ojo, MD, PhD;4 Lawrence Y. Agodoa, MD;5 Kenneth A. Jamerson, MD 6
}

Hypertension is more prevalent and severe in African descendent populations living outside Africa than in any other population. Given this greater burden of hypertension in blacks, it is increasingly necessary to refine strategies to prevent the disorder as well as improve its treatment and control. This review assesses results from clinical trials on lifestyle and pharmacologic interventions to identify which approaches most effectively prevent adverse hypertension-related outcomes in African descendent populations. The Dietary Approaches to Stop Hypertension (DASH) study provided evidence that a carefully controlled diet rich in fruits, vegetables, low-fat dairy foods, and reduced in saturated fat, total fat, and cholesterol (i.e., the DASH diet) reduces blood pressure in blacks and is well accepted. The combination of the DASH diet with reduction in dietary sodium below $100 \mathrm{mmol} / \mathrm{d}$ may provide a reduction in blood pressure beyond that reached by the DASH diet alone. Physical exercise and interventions to reduce psy-

From the Department of Medicine, Federal University of Bahia, Brazil;:1 Departments of Epidemiology and Health Behavior and Health Education, University of Michigan, Ann Arbor, MI; ${ }^{2}$ University Renal Research and Education Association (URREA), Ann Arbor, MI; 3 Division of Nephrology, University of Michigan, Ann Arbor, MI;4 National Institute of Diabetes and Digestive and Kidney Diseases, Bethesda, MD; and Division of Hypertension and Hyperlipidemia, University of Michigan, Ann Arbor, MI6

Address for correspondence:

Antonio Alberto Lopes, MD, PhD, Rua Mar. Flariano 448, Apartment 1301, Canela, Salvador, BA CEP: 40110-010, Brazil

E-mail:aaslopes@ufba.br

Manuscript received September 25, 2002;

revised October 28, 2002;

accepted November 18, 2002
ID: 1736 chological stress may also reduce blood pressure in blacks. Strong evidence from numerous studies is a compelling argument for continuing to recommend diuretics and $\beta$ blockers as first-line antibypertensive therapy for persons of all races. Some new studies also favor angiotensin-converting enzyme inhibitors as first-line antihypertensive drugs. The African American Study of Kidney Disease and Hypertension provided evidence that an angiotensin-converting enzyme inhibitor-based treatment program is more beneficial than calcium channel blockers and $\beta$ blockers in reducing the progression of renal failure in blacks with bypertensive nephropathy. Studies in patients with diabetes have also shown evidence that both angiotensinconverting enzyme inhibitors and angiotensin receptor antagonists are more effective than other classes of antihypertensives in reducing adverse renal events. Studies to evaluate the effects of the new antibypertensives in improving outcomes in blacks living outside the United States are needed.

(J Clin Hypertens. 2003;5:393-401)

๑2003 Le Jacq Communications, Inc.

G pidemiologic studies have shown that the prevaClence of hypertension is higher among blacks than among whites.1,2 The racial difference is even more remarkable for the most severe forms and complications of hypertension. ${ }^{3-5}$ Malignant hypertension, an easily preventable complication of high blood pressure, is still frequent in some African descendent populations.6,7 The excess risk of hypertension and related complications in blacks (compared with whites) has been described in studies from Europe, North America, the Bahamas, and South America. ${ }^{1,8-11}$ The studies that are more consistent regarding the black-white difference in hypertension, however, are those from the United States 
and Brazil, the countries with the largest African descendent populations outside Africa.

Table I summarizes data from two studies ${ }^{1,9}$ that compared the prevalence of hypertension in blacks and whites. One study, the Hypertension Detection and Follow-Up Program (HDFP), ${ }^{1}$ was conducted in 14 US communities and the other in the city of São Paulo, Brazil. ${ }^{9}$ In the US study, the prevalence of hypertension as defined by a diastolic blood pressure (DBP) $\geq 95 \mathrm{~mm} \mathrm{Hg}$ was approximately 2.3-times higher in blacks than in whites. In Brazil, the percentage of workers with DBP $\geq 95 \mathrm{~mm} \mathrm{Hg}$ was almost twice as high in blacks than in whites. In both studies, the black-white prevalence ratio of hypertension increased when higher cut points were used for DBP.

These racial disparities in hypertension, observed for different societies in the Western hemisphere, point to the need to refine strategies to both prevent hypertension and improve its control in populations of African descent. Toward this end, the current review assesses results from clinical trials on lifestyle and pharmacologic interventions in order to identify approaches deserving a greater emphasis in the treatment of hypertension in blacks.

\section{LIFESTYLE MODIFICATION}

Lifestyles such as poor dietary habits, excess alcohol consumption, and lack of exercise have been associated with hypertension.12-15 A greater emphasis on lifestyle modification in blacks is justifiable. Blacks (compared with whites), for example, have a higher prevalence of obesity and lower dietary intakes of potassium. ${ }^{16,17}$

Several intervention studies have been developed to assess the efficacy of lifestyle modification in reducing blood pressure levels. Results of studies on dietary intervention, weight loss, physical exercise, reduction of excessive alcohol consumption, and control of psychologic stress are described below.

\section{The DASH Diet}

The Dietary Approaches to Stop Hypertension (DASH) study ${ }^{18}$ was a randomized, controlled clinical trial developed to assess the effects of dietary patterns on blood pressure. Participants were assigned to consume either a diet typical of intake in the United States or a controlled diet rich in fruits, vegetables, low-fat dairy foods, and reduced in saturated fat, total fat, and cholesterol (i.e., the DASH diet). All food was provided. The daily intake of potassium provided by the DASH diet was higher than the average intake in the United States. A total of 459 adults with systolic blood pressure (SBP) $<160 \mathrm{~mm} \mathrm{Hg}$ and DBP 80-95 $\mathrm{mm} \mathrm{Hg}$ were enrolled. Blacks comprised approximately $60 \%$ of the sample. ${ }^{18}$ The DASH diet significantly reduced both the SBP and DBP. Among blacks, the DASH diet was associated with a blood pressure decrease of $6.9 / 3.7 \mathrm{~mm} \mathrm{Hg}(p<0.001)$. Among whites, blood pressure decreased by $3.3 / 2.4 \mathrm{~mm} \mathrm{Hg}(p<0.01)$. In blacks, but not in whites, the decrease in blood pressure (both SBP and DBP) was statistically significant among both hypertensive and normotensive participants. Thus, a stronger beneficial effect of the DASH diet was observed for blacks. The DASH study provided evidence that a diet rich in fruits, vegetables, and low-fat dairy foods and reduced in saturated fat, total fat, and cholesterol not only reduces blood pressure in blacks, but is also accepted by them. ${ }^{19}$ However, it is important to re-emphasize that the DASH study provided participants with all of their food and was carefully controlled. Thus the impressive results observed in the group that received the DASH diet may not be generalized to clinical practice.

\section{Dietary Sodium Reduction}

Hypertensive patients who succeed in reducing dietary sodium intake generally require fewer antihypertensive drugs. ${ }^{20}$ In patients on angiotensin-converting enzyme (ACE) inhibitors, reduction in dietary sodium was found to be as effective as a thiazide diuretic in

\begin{tabular}{|c|c|c|c|c|c|}
\hline \multirow[b]{2}{*}{ STUDY } & \multirow[b]{2}{*}{ SETTING } & \multicolumn{4}{|c|}{$\begin{array}{c}\text { PREVALENCE OF } \\
\text { HYPERTENSION }(\%)\end{array}$} \\
\hline & & $\begin{array}{l}\text { DBP TO DEFINE } \\
\text { HYPERTENSION }\end{array}$ & BLACKS & WHITES & PR \\
\hline \multirow{2}{*}{$\begin{array}{l}\text { Hypertension Detection and } \\
\text { Follow-up Program }\end{array}$} & \multirow{2}{*}{ United States } & $\geq 95$ & 24.9 & 10.8 & 2.3 \\
\hline & & $\geq 115$ & 3.9 & 0.7 & 5.6 \\
\hline \multirow{2}{*}{ Hypertension in Brazilian Workers } & \multirow{2}{*}{$\begin{array}{l}\text { São Paulo, } \\
\text { Brazil }\end{array}$} & $\geq 90$ & 29.2 & 16.7 & 1.8 \\
\hline & & $\geq 105^{*}$ & 11.7 & 3.3 & 3.5 \\
\hline
\end{tabular}


lowering blood pressure and has the additional advantage of preventing hypokalemia. 21

A randomized clinical trial ${ }^{22}$ was conducted in 412 participants ( $57 \%$ blacks) to assess the effects of different levels of sodium in conjunction with the DASH diet. The reduction in sodium intake from the current recommended level of $100 \mathrm{mmol} / \mathrm{d}$ to a target level of $50 \mathrm{mmol} / \mathrm{d}$, in conjunction with the DASH diet, led to a mean reduction in SBP of 7.1 $\mathrm{mm} \mathrm{Hg}$ and $11.5 \mathrm{~mm} \mathrm{Hg}$ in normotensive and hypertensive participants, respectively. The conclusion was that the reduction in sodium intake below $100 \mathrm{mmol} / \mathrm{d}$ caused reduction in the blood pressure beyond that produced by the DASH diet alone. Importantly, this effect was independent of the presence of hypertension, race, and gender. However, this level of sodium restriction (i.e., $50 \mathrm{mmol} / \mathrm{d}$ ) may be difficult to achieve in large numbers of subjects.

\section{Supplementation of Potassium}

Evidence from randomized clinical trials also suggests that potassium supplementation reduces blood pressure, and the results are more striking in blacks. ${ }^{23}$ Moreover, the increase of dietary intake of potassium in blacks was found to attenuate the increase in blood pressure induced by mental stress. ${ }^{24}$ These findings emphasize the importance of maintaining an adequate intake of potassium for controlling high blood pressure; this may be particularly important for blacks. The current recommendation is a daily potassium intake of approximately $90 \mathrm{mmol} / \mathrm{d} .25$ A study in hypertensive men found that the average 24-hour potassium excretion was only $45 \mathrm{mEq}$ among 407 black and $73 \mathrm{mEq}$ among 216 white participants. ${ }^{17}$

\section{Physical Exercise and Psychological Stress}

In a randomized clinical trial that enrolled black Americans with stage 3 hypertension, aerobic exercise of moderate intensity was associated with a significant decrease in blood pressure. ${ }^{26}$ Moreover, after 16 weeks of exercise, significant reductions in the thickness of the interventricular septum, in the left ventricular mass, and in left ventricular index were observed only in the group assigned to aerobic exercise.

Studies have been conducted to assess the efficacy of techniques directed at stress reduction in controlling blood pressure in blacks. Some of the more promising results are from trials on transcendental meditation. ${ }^{27,28}$ The use of this technique has resulted in significant reductions in blood pressure and regression in left ventricular hypertrophy. In a randomized, controlled, single-blind trial ${ }^{28}$ with 3 months of follow-up that enrolled 213 African Americans, transcendental meditation led to a mean reduction in SBP and DBP of $10.7 \mathrm{~mm} \mathrm{Hg}$ and $6.4 \mathrm{~mm} \mathrm{Hg}$, respectively. Since the studies on physical exercise and transcendental meditation were short-term trials (2-6 months) and usually involved small number of subjects, it is not clear if these interventions can effectively control hypertension for longer periods.

\section{Alcohol Consumption}

The Pitt County Study, ${ }^{29}$ a prospective cohort study among 970 blacks aged 25-50 years at baseline in 1988, found that changes in the drinking status (i.e., from abstainer to drinker) during a 5-year follow-up period was associated with a larger increase in blood pressure. The SBP increase among former abstainers who initiated alcohol consumption was $6.2 \mathrm{~mm} \mathrm{Hg}$ greater than the increase observed for continued abstainers. Another prospective cohort study 30 of 6817 white and 1320 black participants aged 45-64 years was developed in four communities in the United States to assess the risk of hypertension associated with alcohol consumption. Baseline data were collected from 1987-1989. For black men, the odds of being hypertensive (adjusted for age, body mass index, education, physical activity, and diabetes) among heavy drinkers (i.e., $>3$ drinks per day) were more than two times higher than the odds among those who have not consumed alcohol during 6 years of follow-up (odds ratio [OR], 2.3; 95\% confidence interval [CI], 1.1-4.9). The consumption of low to moderate amounts of alcohol ( $\leq 3$ drinks per day) was also significantly associated with an increased risk of hypertension among black men (adjusted OR, 1.7; 95\% CI, 1.1-2.6). A recent meta-analysis ${ }^{31}$ that included 15 randomized clinical trials showed that reduction in alcohol consumption is efficacious in controlling high blood pressure. Overall, alcohol reduction was associated with a significant reduction of $3.3 \mathrm{~mm} \mathrm{Hg}$ in $\mathrm{SBP}$ and $2.0 \mathrm{~mm} \mathrm{Hg}$ in DBP. Although the trials included in the meta-analysis were targeted to predominantly white populations, the results support a greater emphasis on interventions to reduce excessive alcohol consumption in populations at high risk of hypertension and related complications, such as African Americans.

\section{Weight Loss}

Obesity is more prevalent in black than in white Americans and is considered one important contributor to the racial gap in hypertension. ${ }^{16}$ Studies that enrolled blacks give support to weight loss as efficacious in controlling high blood pressure in overweight hypertensives and improving the response to pharmacologic interventions. The Trial of Antihypertensive Interventions and Management 32 enrolled 587 persons ( $33 \%$ blacks) with a mean age 
of 48 years to assess the long-term benefit of weight loss to control blood pressure. Participants were at $110 \%-160 \%$ of ideal weight and had mean DBPs between $90-100 \mathrm{~mm} \mathrm{Hg}$. They were randomized to a usual diet or to a weight loss diet and within each diet group to placebo, chlorthalidone $(25 \mathrm{mg} / \mathrm{d})$, or atenolol $(50 \mathrm{mg} / \mathrm{d})$. The need for additional antihypertensive medications to maintain DBP $<90 \mathrm{~mm} \mathrm{Hg}$ was considered treatment failure. Long-term weight loss was associated with an $\approx 23 \%$ reduction in treatment failure compared with those receiving placebo or low-dose thiazide diuretics or a $\beta$ blocker. In a substudy of the Hypertension Optimal Treatment (HOT) study, 33102 patients (41 blacks) who had a body mass index $\geq 27 \mathrm{~kg} / \mathrm{m}^{2}$ were randomized to a weight loss group (32 whites, 19 blacks) or to a control group ( 29 whites, 22 blacks). The patients who were also randomized to the weight loss group used a significantly smaller number of medication steps to reach target blood pressure.

\section{PHARMACOLOGIC INTERVENTIONS}

Because blacks are at higher risk for hypertension and its complications, they may require more medications to control blood pressure than whites. Three issues should be taken into account when considering pharmacologic interventions for a specific patient: 1 ) when to introduce antihypertensive drugs; 2 ) what type of antihypertensive or combination of drugs should be used; and 3) what is the target blood pressure goal that provides optimal protection against end-organ damage.

\section{When to Start Pharmacologic Interventions}

The current evidence supports the initiation of pharmacologic treatment for stage 1 hypertension (i.e., blood pressure of 140-159/90-99 mm Hg) in the presence of target organ damage or clinical cardiovascular disease, i.e., left ventricular hypertrophy, angina or prior myocardial infarction, prior coronary revascularization, heart failure, stroke, nephropathy, peripheral arterial disease, retinopathy. Considering the higher risk of target organ damage/clinical cardiovascular disease in blacks, it is expected that a large fraction of blacks at stage 1 will meet this recommendation to initiate pharmacologic treatment in addition to lifestyle modifications. Pharmacologic treatment should also be introduced for stage 1 hypertensives in the presence of risk factors for target organ complications (i.e., smoking, dyslipidemia, diabetes mellitus, age $>60$ years, male gender, and postmenopausal women) when blood pressure is not reduced to levels $\approx 130 / 85 \mathrm{~mm} \mathrm{Hg}$ with lifestyle modification. ${ }^{25}$ For adults with hypertension at stages 2 or 3 (blood pressure $\geq 160 / \geq 100 \mathrm{~mm} \mathrm{Hg}$ ), drug therapy should be promptly introduced. ${ }^{25}$

\section{Antihypertensive Regimen}

Studies that compare racial differences in the response to different classes of antihypertensive drugs used as monotherapy have been used as evidence to support recommendations about which drugs should be prescribed for blacks with hypertension. These studies have shown that the antihypertensive response to $\beta$ blockers and ACE inhibitors, when used as monotherapy, is less for blacks than for whites. It should be noted, however, that the response to specific antihypertensive medications varies a great deal among individuals of any race. Moreover, combinations of drugs such as a diuretic with a $\beta$ blocker or an ACE inhibitor with a diuretic narrow or eliminate racial differences in blood pressure reduction. ${ }^{34,35}$ It is also worth noting that, although the capacity to reduce blood pressure is important in the selection of an antihypertensive drug, it may not be the final answer regarding the actual contribution of the drug to reduce the risk of adverse outcomes caused by uncontrolled hypertension.

Studies in predominantly white populations (e.g., the Captopril Prevention Project [CAPPP], 36 International Nifedipine GITS study: Intervention as a Goal in Hypertension Treatment [INSIGHT], 37 Nordic Diltiazem [NORDIL] Study, ${ }^{38}$ Swedish Trial in Old Patients with Hypertension [STOP-2] ${ }^{39}$ ) were developed to compare newer antihypertensives, such as calcium channel blockers [CCBs] and ACE inhibitors, with thiazide diuretics and $\beta$ blockers regarding their effects on reducing the risk of hypertension-related cardiovascular outcomes. ${ }^{36-39}$ In general the risks of cardiovascular outcomes were found to be similar between regimens based on newer antihypertensives (i.e., CCBs and ACE inhibitors) and older antihypertensives (i.e., thiazide diuretics and $\beta$ blockers).

More recently, clinical trials have been developed with emphasis on black populations to compare outcomes between antihypertensive regimens. One of these trials, the African American Study of Kidney Disease and Hypertension (AASK), ${ }^{40,41}$ was specifically designed to study blacks with hypertensive nephropathy and renal insufficiency, without evidence of accelerated or malignant hypertension within 6 months. Another recent study, the Antihypertensive and Lipid-Lowering Treatment to Prevent Heart Attack Trial (ALLHAT), 42 was designed to have an adequate representation of blacks with hypertension, the objective being to compare the results of treatment initiated with a diuretic to a CCB, ACE inhibitor, or $\alpha$ blocker on the risk of cardiovascular outcomes. 
The African American Study of Kidney Disease and Hypertension (AASK). The AASK 40,41 was designed as a randomized clinical trial to compare the progression of hypertensive kidney disease among treatment regimens initiated with one of three antihypertensive drug classes: $\beta$ blocker (metoprolol), CCB (amlodipine), or an ACE inhibitor (ramipril) and also to compare outcomes of two blood pressure goals: mean arterial pressure (MAP) $<92 \mathrm{~mm} \mathrm{Hg}$ (blood pressure, $128 / 79 \mathrm{~mm} \mathrm{Hg}$ ) and MAP of 102-107 mm Hg (blood pressure, 140/90 mm Hg). If the blood pressure goal was not achieved while the participants were taking one of the three study drugs, additional unmasked drugs were added in the following recommended order: furosemide, doxazosin mesylate, clonidine hydrochloride, hydralazine hydrochloride, and minoxidil. The 1094 participants were African Americans with ages between 18-70 years. All randomized patients met the clinical criteria for hypertensive renal disease and had a glomerular filtration rate (GFR) ranging from $20-65 \mathrm{~mL} / \mathrm{min} / 1.73 \mathrm{~m}^{2}$. To date, AASK is the largest clinical trial developed to assess renal outcomes in patients with hypertensive nephropathy. Another important characteristic of the AASK is that it is the first clinical trial with sufficient sample size to evaluate the effects of inhibition of the renin-angiotensin-aldosterone system in blacks.

An interim analysis of AASK was published 40 after discontinuation of the amlodipine arm due to the observation that the decline in mean GFR was slower and the risk of three outcomes (reduction in GFR by $50 \%$ or by $25 \mathrm{~mL} / \mathrm{min} / 1.73 \mathrm{~m}^{2}$, end-stage renal disease [ESRD], or death) was smaller for patients allocated to the ramipril- and metoprolol-based treatment groups than for those patients allocated to the amlodipinebased treatment group. Among patients with an estimated level of proteinuria $>300 \mathrm{mg} / \mathrm{d}$, the ACE inhibitor group had a $36 \%$ slower mean decline in GFR over 3 years $(p=0.006)$. As shown in the Figure, the cumulative risk of renal events and death was lower in the ramipril-based treatment group than in the amlodipine-based treatment group. The adjusted risk reduction was $38 \%(p=0.005)$ for the composite index of clinical end points and $41 \%(p=0.007)$ for ESRD or death. The results of the AASK study also suggest a smaller risk of renal outcomes in patients on ACE inhibitors than in those on $\beta$ blockers. ${ }^{41}$ It should be remembered that patients on the study drugs usually received other agents to achieve goal blood pressures.

Antihypertensive and Lipid-Lowering Treatment to Prevent Heart Attack Trial (ALLHAT). The recently completed ALLHAT,42,43 which enrolled 42,418 high-risk patients with hypertension aged 55 years or older, is the largest trial to assess the cardioprotective benefits of specific drug classes. Originally at least $55 \%$ of ALLHAT participants were to be black. However, the actual proportion was $36 \%$. This is still much higher than the proportions typically reached in clinical trials focusing on hypertension treatment in the United States.

ALLHAT compared a diuretic (chlorthalidone), a CCB (amlodipine), an ACE inhibitor (lisinopril), and an $\alpha$-adrenergic blocker (doxazosin). The primary outcome was a composite of fatal coronary heart disease and nonfatal myocardial infarction. The doxazosin arm was discontinued because of an increased risk of cardiovascular events when compared with the diuretic arm. ${ }^{42}$ Table II shows the relative risks of outcomes with doxazosin compared with chlorthalidone in the full sample and in the subgroup of black subjects. In the full sample, the risk of combined cardiovascular events (i.e., coronary heart disease death, nonfatal myocardial infarction, stroke, coronary revascularization procedures, angina or peripheral arterial disease) was $25 \%$ higher (relative risk, $1.25 ; p<0.05$ ) in the doxazosin than in the chlorthalidone group. 42 The risks of heart failure and stroke were also higher in the doxazosin group. As shown in Table II, the higher risk of cardiovascular outcomes in the doxazosin group compared with the chlorthalidone group was observed for the whole sample 42 and for both blacks and whites (K. Jamerson, MD personal communication, 2002).

In ALLHAT, chlorthalidone, in general, was also superior to lisinopril and amlodipine.43 Among blacks, the risks of stroke, combined coronary heart disease (coronary heart disease death, nonfatal myocardial infarction, coronary revascularization procedures, or angina with hospitalization), combined cardiovascular disease, and heart failure were

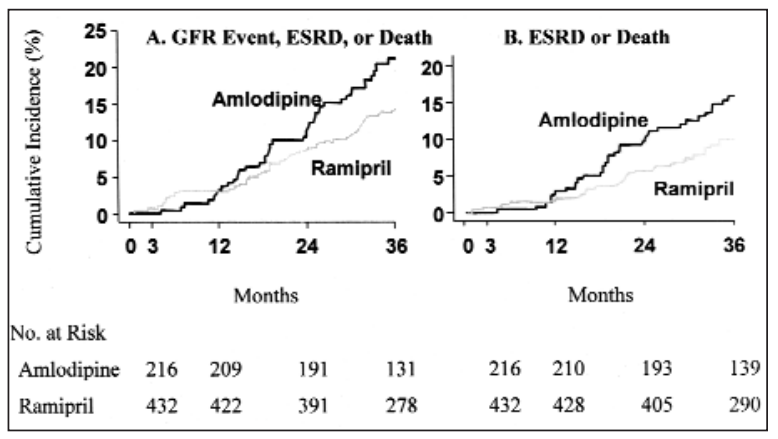

Figure. The African American Study of Kidney Disease and Hypertension-cumulative incidence of renal events and death between the amlodipine and ramipril group; GFR event=reduction in glomerular filtration rate by $50 \%$ or by $25 \mathrm{~mL} / \mathrm{min} / 1.73 \mathrm{~m}^{2}$ from the mean of the two baseline GFRs; ESRD=end-stage renal disease; Reprinted with permission from JAMA. 2001;285: 2719-2728.40 
Table II. ALLHAT Study-Relative Risks of Outcomes by Comparing Doxazosin Versus Chlorthalidone in the Whole Sample and in Black Subjects

\begin{tabular}{|lcc|}
\hline & \multicolumn{2}{c|}{ RELATIVE RISK (95\% CONFIDENCE INTERVAL) } \\
OUTCOME & WHOLE SAMPLE & BLACKS \\
\hline Fatal CHD or nonfatal MI* & $1.03(0.90-1.17)$ & $1.17(0.91-1.51)$ \\
Combined CVD** & $1.25(1.17-1.33)$ & $1.37(1.22-1.55)$ \\
Cardiac heart failure & $2.04(1.79-2.33)$ & $2.17(1.72-2.73)$ \\
Stroke & $1.19(1.01-1.40)$ & $1.33(1.03-1.73)$ \\
\hline ALLHAT=Antihypertensive and Lipid-Lowering Treatment to Prevent Heart Attack Trial; CHD=coronary heart \\
disease; MI=myocardial infarction; CVD=cardiovascular disease; *fatal CHD or nonfatal MI was the primary outcome; \\
"*combined CVD consists of CHD death, nonfatal MI, stroke, coronary revascularization procedures, angina (treated \\
in hospital or as outpatient), and peripheral arterial disease (inhospital or outpatient revascularization)
\end{tabular}

higher for patients on lisinopril than for those on chlorthalidone. For the whole ALLHAT group and for blacks, the risks of primary outcome and death for any cause were not different between chlorthalidone and lisinopril. For amlodipine vs. chlorthalidone, the risks of outcomes were similar except for a significantly higher risk of heart failure with amlodipine.

Trials in Diabetic Patients. The prevalence of diabetes, particularly type 2 diabetes, is higher in black than in white Americans. ${ }^{44}$ Type 2 diabetes is frequently associated with hypertension (particularly among blacks) and represents an important risk factor of cardiovascular disease, renal failure, and death. In the United States, type 2 diabetes is a major cause of ESRD, particularly among black women. 45 Part of the excess risk of ESRD due to diabetes in blacks is likely due to uncontrolled hypertension. ${ }^{46}$

Trials in predominantly white populations suggest that the use of an ACE inhibitor-based program delays progression of diabetic nephropathy. ${ }^{47,48}$ In addition, there are data to suggest that the control of blood pressure may be more important than the class of antihypertensive used in preventing complications in diabetics with hypertension. 49

More recently, clinical trials ${ }^{50-52}$ have been developed in patients with type 2 diabetes to evaluate the efficacy of angiotensin II antagonists (or angiotensin II receptor blockers [ARBs]) in reducing the risk of renal and cardiovascular events: the Irbesartan in Patients with Type 2 Diabetes and Microalbuminuria Study (IRMA II), sample size of $590^{50}$; the Reduction of Endpoints in NIDDM (non-insulin-dependent diabetes mellitus) with the Angiotensin II Antagonist Losartan (RENAAL), sample size of 1318 patients ${ }^{51}$; and the Irbesartan Diabetic Nephropathy Trial (IDNT), sample size of 1715 patients. 52 In the IRMA II study the proportion of nonwhite participants was small $(4.2 \%)$. In this study the ARB irbesartan was compared with a regimen that did not include an ACE inhibitor or ARB. The irbesartan-based treatment was associated with a significant reduction in the development of overt diabetic nephropathy (i.e., increasing degrees of albuminuria).

The proportions of black participants in the RENAAL and IDNT were $17.4 \%$ and $13.3 \%$, respectively. The RENAAL compared the ARB losartan to a regimen that did not include an ACE inhibitor or ARB, and the IDNT compared an ARB, irbesartan-based regimen to the CCB amlodipine and a regimen that did not include either of the study drugs or an ACE inhibitor. In both studies a reduction in risk of ESRD, cardiovascular events, and death in patients using ARBs was observed. Unfortunately, the specific results of the effects of an ARB-based program in the black participants of the RENAAL and IDNT trials were not reported. It is important to note that in all of the above studies, more than $70 \%$ of the patients were receiving a diuretic in addition to the study drugs.

\section{Target Blood Pressure}

The recently completed AASK study also examined the effect of tighter blood pressure control on progression to renal failure. ${ }^{41}$ The study compared a MAP of less than $92 \mathrm{~mm} \mathrm{Hg}$ to a MAP of 102-107 $\mathrm{mm} \mathrm{Hg}$ in patients with hypertensive nephropathy. In this trial the percent change in geometric mean proteinuria during 48 months of follow-up was significantly lower for blood pressure goal $(p<0.001) .41$

However, the mean GFR slope from baseline through 4 years and the risk of clinical composite outcome (i.e., reduction in GFR $\geq 50 \%$ or $\geq 25$ $\mathrm{mL} / \mathrm{min} / 1.73 \mathrm{~m}^{2}$ from baseline, ESRD, or death) did not differ significantly between the two blood pressure goals. 
Other clinical trials have also been designed to assess the impact of aggressive blood pressure control in reducing the risk of major outcomes: the HOT study, 53 the Appropriate Blood Pressure Control in Diabetes (ABCD) trial, 54 and the United Kingdom Prospective Diabetes Study (UKPDS). 55 Among diabetic patients enrolled in the HOT study, the incidence of cardiovascular events was significantly lower (trend test, $p=0.005$ ) in the target-level group $\leq 80 \mathrm{~mm} \mathrm{Hg}$ than in the group $\leq 90$ $\mathrm{mm} \mathrm{Hg}$. The results for the nondiabetic patients were not presented in the original publication of the HOT study53; however, a reanalysis of the HOT study 56 showed that the nondiabetic hypertensive patients allocated to a DBP goal $\leq 80 \mathrm{~mm}$ $\mathrm{Hg}$ had a marginally significant increase of $35.5 \%$ in cardiovascular mortality than the group allocated to a DBP goal $\leq 90 \mathrm{~mm} \mathrm{Hg}$.

In the ABCD and the UKPDS all the patients had type 2 diabetes. Among 470 patients with hypertension (13.8\% African Americans) in the ABCD trial, there was no significant difference between intensive blood pressure control (goal DBP of $75 \mathrm{~mm} \mathrm{Hg}$ ) and moderate control (goal DBP of $80-89 \mathrm{~mm} \mathrm{Hg}$ ) with regard to progression from normoalbuminuria to microalbuminuria or microalbuminuria to overt albuminuria. All-cause mortality, however, was significantly lower in patients receiving intensive blood pressure control. In the UKPDS, the risk of death due to diabetes, stroke, and microvascular disease was significantly lower in the group with tighter $(144 / 82 \mathrm{~mm}$ $\mathrm{Hg}$ vs. $154 / 87 \mathrm{~mm} \mathrm{Hg}$ ) control.

Inconsistent results across AASK, $\mathrm{ABCD}$, UKPDS, and the HOT study may be due to differences in patient characteristics, blood pressure levels used to define tighter control, and the outcomes of interest among the studies. The target populations of the AASK and the ABCD were patients with hypertensive and diabetic nephropathy, respectively. Neither study supports the hypothesis that a reduction of DBP to levels around $75 \mathrm{~mm} \mathrm{Hg}$ is more beneficial than the reduction to a more conventional level (i.e., DBP levels around $85 \mathrm{~mm} \mathrm{Hg}$ ) in slowing the progression of renal failure in diabetic and hypertensive nephropathies. Similar to the ABCD, the UKPDS also studied type 2 diabetic patients. However, in the UKPDS the benefit that may be attributed to tighter blood pressure control regarding microvascular complication was more impressive than in ABCD. Additionally, in the UKPDS the mean blood pressure level reached in the less tight control group ( $<154 / 87 \mathrm{~mm} \mathrm{Hg}$ ) was higher than in the ABCD study $(138 / 86 \mathrm{~mm} \mathrm{Hg})$. In the HOT study the beneficial effect of tighter blood pressure control ( $\leq 80$ vs. $\leq 90 \mathrm{~mm} \mathrm{Hg}$ ) was observed only in a subgroup analysis among diabetics, which increases the probability of type 1 error.

\section{FROM RESEARCH TO CLINICAL PRACTICE}

In order to improve the treatment of hypertension in blacks, the gap between research and clinical practice must be closed. Specifically, it is necessary to increase the rate of early detection of hypertension and also to assure that all hypertensive blacks receive the best available treatment. In order to reach these objectives we must remove barriers that impede improvement in rates of awareness, treatment, and control of hypertension in blacks.

In the United States, factors related to the health care system and the patients' health-related behaviors have been associated with adherence to treatment for high blood pressure and with the presence of severe, uncontrolled hypertension among inner-city minorities, especially blacks. ${ }^{57} \mathrm{~A}$ large fraction of hypertensive blacks still do not have health insurance and a primary care physician. These patients are more likely to have their blood pressure checked and receive prescriptions for blood pressure medication in emergency rooms than in the physicians' offices or clinics. ${ }^{57}$ In Brazil a large fraction of hypertensive patients are also poor and black. As observed for black Americans, most of these Brazilian patients do not have a primary care physician and use emergency services as the main source of care for hypertension. ${ }^{5}$

It is important to guarantee access to high-quality medical care for poor blacks and other underprivileged minority groups. It is also important to provide education for patients and families in addition to health care providers about the best interventions to control hypertension. As has been shown when blacks and whites receive a similar quality of heath care, the racial gap in hypertension-related complications is eliminated. ${ }^{59}$ It is also important to note that less costly antihypertensive medications (e.g., diuretics) have been proved to be as effective as or even better than more costly medications such as CCBs and ACE inhibitors in reducing the risk of cardiovascular events in blacks. By reducing the cost of treatment, the number of black hypertensive patients achieving adequate blood pressure control should increase.

\section{CONCLUSIONS}

Observational studies outside Africa have shown that hypertension is more prevalent and severe in blacks. However, the existing data indicate that the burden of hypertension in blacks may be reduced if antihypertensive treatment is pursued vigorously to goal blood pressure levels and oriented by the 
patient's characteristics. AASK 40,41 shows evidence that antihypertensive treatment plays an important role in reducing the rate of deterioration of renal function in blacks with chronic renal failure due to nonmalignant forms of hypertension, a situation that in the past was believed to progress to ESRD independently of blood pressure control. 60

The DASH study 18 showed that a diet rich in lowfat dairy food, vegetables, and fruits and reduced in saturated fat, total fat, and cholesterol (i.e., the DASH diet) could reduce both SBP and DBP in blacks. The effect of this type of diet on blood pressure reduction does not depend on weight loss and may be intensified by sodium restriction. The daily intake of potassium provided by the DASH diet is higher than the average intake of black Americans and may bring additional health benefits. In the clinical trial, the DASH diet was well accepted by blacks. Aerobic exercise and strategies at stress reduction (such as transcendental meditation) may also improve hypertension control in blacks. Larger and longer-term clinical trials are needed to determine the actual benefit of these approaches in the treatment of hypertensive blacks.

The growing evidence supports the use of diuretics and $\beta$ blockers as first-line antihypertensive medication for patients of all races. The data also support the use of an ACE inhibitor (usually with a diuretic) in hypertensive blacks at higher risk of ESRD, i.e., those with renal failure. As shown in AASK, ESRD and death were significantly lower in the group treated with an ACE inhibitor-based regimen than in the group treated with a CCB-based regimen. Studies in predominantly white populations with type 2 diabetes also support the efficacy of an ARB-based regimen in preventing renal events.

To improve the treatment of hypertension in blacks, the scientific evidence should be integrated with clinical practice. It is important to assure that health professionals will apply the information from clinical trials to their patients and guarantee a high rate of adherence of hypertensive blacks to the treatment recommendations.

Acknowledgment: Antonio Alberto Lopes was supported by a grant (BEX2018/00-4) from the Fundação Coordenação de Aperfeiçoamento de Pessoal de Nivel Superior (CAPES), Ministry of Education of Brazil.

\section{REFERENCES}

1 HDFP Cooperative Group. Blood pressure studies in 14 communities. A two-stage screen for hypertension. JAMA. 1977;237:2385-2391.

2 Lopes AA. Hipertensão arterial: fatores étnicos e raciais. J Bras Nefrol. 1999;21:82-84.

3 Lopes AA, Port FK, James SA, et al. The excess risk of treated end-stage renal disease in blacks in the United States. J Am Soc Nephrol. 1993;3:1961-1971.
4 Kittner SJ, White LR, Losonczy KG, et al. Black-white differences in stroke incidence in a national sample. The contribution of hypertension and diabetes mellitus. JAMA. 1990;264:1267-1270.

5 Koren MJ, Mensah GA, Blake J, et al. Comparison of left ventricular mass and geometry in black and white patients with essential hypertension. Am J Hypertens. 1993;6:815-823.

6 Milne FJ, James SH, Veriava Y. Malignant hypertension and its renal complications in black South Africans. S Afr Med J. 1989;76:164-167.

7 Ramos O. Malignant hypertension: the Brazilian experience. Kidney Int. 1984;26:209-217.

8 Primatesta P, Bost L, Poulter NR. Blood pressure levels and hypertension status among ethnic groups in England. J Hum Hypertens. 2000;14:143-148.

9 Ribeiro MB, Ribeiro AB, Neto CS, et al. Hypertension and economic activities in Sao Paulo, Brazil. Hypertension. 1981;3:II233-II237.

10 James SA, de Almeida-Filho N, Kaufman JS. Hypertension in Brazil: a review of the epidemiological evidence. Ethn Dis. 1991;1:91-98.

11 Moser M, Morgan R, Hale M, et al. Epidemiology of hypertension with particular reference to the Bahamas, Part I: preliminary report of blood pressure and possible etiologic factors. Am J Cardiol. 1959;4:727-733.

12 Ascherio A, Hennekens C, Willett WC, et al. Prospective study of nutritional factors, blood pressure, and hypertension among US women. Hypertension. 1996;27:1065-1072.

13 Marmot MG, Elliott P, Shipley MJ, et al. Alcohol and blood pressure: the INTERSALT study. BMJ. 1994;308:1263-1267.

14 Neser WB, Thomas J, Semenya K, et al. Obesity and hypertension in a longitudinal study of black physicians: the Meharry Cohort Study. J Chronic Dis. 1986;39:105-113.

15 Ainsworth BE, Keenan NL, Strogatz DS, et al. Physical activity and hypertension in black adults: the Pitt County Study. Am J Public Health. 1991;81:1477-1479.

16 Kumanyika S. Obesity in black women. Epidemiol Rev. 1987;9:31-50.

17 Veterans Administration Cooperative Study Group on Antihypertensive Agents. Urinary and serum electrolytes in untreated black and white hypertensives. J Chronic Dis. 1987;40:839-847.

18 Svetkey LP, Simons-Morton D, Vollmer WM, et al. Effects of dietary patterns on blood pressure: subgroup analysis of the Dietary Approaches to Stop Hypertension (DASH) randomized clinical trial. Arch Intern Med. 1999;159:285-293.

19 Vollmer WM, Svetkey LP, Appel LJ, et al. Recruitment and retention of minority participants in the DASH controlled feeding trial. DASH Collaborative Research Group. Dietary Approaches to Stop Hypertension. Ethn Dis. 1998;8:198-208.

20 Beard TC, Cooke HM, Gray WR, et al. Randomised controlled trial of a no-added-sodium diet for mild hypertension. Lancet. 1982;2:455-458.

21 Singer DR, Markandu ND, Cappuccio FP, et al. Reduction of salt intake during converting enzyme inhibitor treatment compared with addition of a thiazide. Hypertension. 1995;25:1042-1044.

22 Sacks FM, Svetkey LP, Vollmer WM, et al. Effects on blood pressure of reduced dietary sodium and the Dietary Approaches to Stop Hypertension (DASH) diet. DASH-Sodium Collaborative Research Group. N Engl J Med. 2001;344:3-10.

23 Brancati FL, Appel LJ, Seidler AJ, et al. Effect of potassium supplementation on blood pressure in African Americans on a lowpotassium diet. A randomized, double-blind, placebo-controlled trial. Arch Intern Med. 1996;156:61-67.

24 Sudhir K, Forman A, Yi SL, et al. Reduced dietary potassium reversibly enhances vasopressor response to stress in African Americans. Hypertension. 1997;29:1083-1090.

25 Joint National Committee on Prevention, Detection, Evaluation, and Treatment of High Blood Pressure. The sixth report. Arch Intern Med. 1997;157:2413-2446.

26 Kokkinos PF, Narayan P, Colleran JA, et al. Effects of regular exercise on blood pressure and left ventricular hypertrophy in 
African-American men with severe hypertension. N Engl J Med. 1995;333:1462-1467.

27 Barnes VA, Treiber FA, Davis H. Impact of transcendental meditation on cardiovascular function at rest and during acute stress in adolescents with high normal blood pressure. $J$ Psychosom Res. 2001;51:597-605.

28 Schneider RH, Staggers F, Alxander CN, et al. A randomised controlled trial of stress reduction for hypertension in older African Americans. Hypertension. 1995;26:820-827.

29 Curtis AB, James SA, Strogatz DS, et al. Alcohol consumption and changes in blood pressure among African Americans. The Pitt County Study. Am J Epidemiol. 1997;146:727-733.

30 Fuchs FD, Chambless LE, Whelton PK, et al. Alcohol consumption and the incidence of hypertension: the Atherosclerosis Risk in Communities Study. Hypertension. 2001;37:1242-1250.

31 Xin X, He J, Frontini MG, et al. Effects of alcohol reduction on blood pressure: a meta-analysis of randomized controlled trials. Hypertension. 2001;38:1112-1117.

32 Davis BR, Blaufox MD, Oberman A, et al. Reduction in longterm antihypertensive medication requirements. Effects of weight reduction by dietary intervention in overweight persons with mild hypertension. Arch Intern Med. 1993;153:1773-1782.

33 Jones DW, Miller ME, Wofford MR, et al. The effect of weight loss intervention on antihypertensive medication requirements in the Hypertension Optimal Treatment (HOT) study. Am J Hypertens. 1999;12:1175-1180.

34 Veterans Administration Cooperative Study Group on Antihypertensive Agents. Racial differences in response to lowdose captopril are abolished by the addition of hydrochlorothiazide. Br J Clin Pharmacol. 1982;14:97S-101S.

35 Prisant LM, Mensah GA. Use of beta-adrenergic receptor blockers in blacks. J Clin Pharmacol. 1996;36:867-873.

36 Hansson L, Lindholm LH, Niskanen L, et al. Effect of angiotensin-converting-enzyme inhibition compared with conventional therapy on cardiovascular morbidity and mortality in hypertension: the Captopril Prevention Project (CAPPP) randomised trial. Lancet. 1999;353:611-616.

37 Brown MJ, Palmer CR, Castaigne A, et al. Morbidity and mortality in patients randomised to double-blind treatment with a longacting calcium-channel blocker or diuretic in the International Nifedipine GITS study: Intervention as a Goal in Hypertension Treatment (INSIGHT). Lancet. 2000;356:366-372.

38 Hansson L, Hedner T, Lund-Johansen P, et al. Randomised trial of effects of calcium antagonists compared with diuretics and beta-blockers on cardiovascular morbidity and mortality in hypertension: the Nordic Diltiazem (NORDIL) study. Lancet. 2000;356:359-365.

39 Lindholm LH, Hansson L, Ekbom T, et al. Comparison of antihypertensive treatments in preventing cardiovascular events in elderly diabetic patients: results from the Swedish Trial in Old Patients with Hypertension-2. STOP Hypertension-2 Study Group. J Hypertens. 2000;18:1671-1675.

40 Agodoa LY, Appel L, Bakris GL, et al. Effect of ramipril vs. amlodipine on renal outcomes in hypertensive nephrosclerosis: a randomized controlled trial. JAMA. 2001;285:2719-2728.

41 Wright JT Jr, Bakris G, Green T, et al. Effect of blood pressure lowering and antihypertensive drug class on progression of hypertensive kidney disease: results from the AASK trial. JAMA. 2002;288:2421-2431.

42 The ALLHAT Officers and Coordinators for the ALLHAT Collaborative Research Group. Major cardiovascular events in hypertensive patients randomized to doxazosin vs chlorthalidone: the hypertensive and lipid-lowering treatment to prevent heart attack trial (ALLHAT). JAMA. 2000;283:1967-1975.

43 The ALLHAT Officers and Coordinators for the ALLHAT Collaborative Research Group. Major outcomes in high-risk hypertensive patients randomized to angiotensin-converting enzyme inhibitor or calcium channel blocker vs diuretic. JAMA.
2002;288:2981-2995.

44 National Center for Health Statistics. Prevalence of Diagnosed Diabetes, Undiagnosed Diabetes, and Impaired Glucose Tolerance in Adults 20-74 Years of Age, United States, 1976-1980. Vital and Health Statistics. Series 11, No. 237. DHHS Pub. No. (PHS) 87-1687. Public Health Service. Washington, DC: US Government Printing Office; 1987.

45 Lopes AA, Port FK. Differences in the patterns of age-specific black/white comparisons between end-stage renal disease attributed and not attributed to diabetes. Am J Kidney Dis. 1995;25:714-721.

46 Chaiken RL, Palmisano J, Norton ME, et al. Interaction of hypertension and diabetes on renal function in black NIDDM subjects. Kidney Int. 1995;47:1697-1702.

47 Viberti G, Mogensen CE, Groop LC, et al. Effect of captopril on progression to clinical proteinuria in patients with insulin-dependent diabetes mellitus and microalbuminuria. European Microalbuminuria Captopril Study Group. JAMA. 1994;271:275-279.

48 Heart Outcomes Prevention Evaluation Study Investigators. Effects of ramipril on cardiovascular and microvascular outcomes in people with diabetes mellitus: results of the HOPE study and MICRO-HOPE substudy. Lancet. 2000;355:253-259.

49 UK Prospective Diabetes Study Group. Efficacy of atenolol and captopril in reducing risk of macrovascular and microvascular complications in type 2 diabetes: UKPDS 39. BMJ. 1998;317:713-720.

50 Parving HH, Lehnert $\mathrm{H}$, Brochner-Mortensen J, et al. The effect of irbesartan on the development of diabetic nephropathy in patients with type 2 diabetes. N Engl J Med. 2001;345:870-878.

51 Brenner BM, Cooper ME, de Zeeuw D, et al. Effects of losartan on renal and cardiovascular outcomes in patients with type 2 diabetes and nephropathy. $N$ Engl J Med. 2001;345:861-869.

52 Lewis EJ, Hunsicker LG, Clarke WR, et al. Renoprotective effect of the angiotensin-receptor antagonist irbesartan in patients with nephropathy due to type 2 diabetes. $N$ Engl J Med. 2001;345:851-860.

53 Hansson L, Zanchetti A, Carruthers SG, et al. Effects of intensive blood pressure-lowering and low-dose aspirin in patients with hypertension: principal results of the Hypertension Optimal Treatment (HOT) randomised trial. HOT Study Group. Lancet. 1998;351:1755-1762.

54 Estacio RO, Jeffers BW, Gifford N, et al. Effect of blood pressure control on diabetic microvascular complications in patients with hypertension and type 2 diabetes. Diabetes Care. 2000;23(suppl 2):B54-B64.

55 UK Prospective Diabetes Study Group. Tight blood pressure control and risk of macrovascular and microvascular complications in type 2 diabetes: UKPDS 38. BMJ. 1998;317:703-713.

56 Lopes AA, Andrade J, Noblat AC, et al. Reduction in diastolic blood pressure and cardiovascular mortality in nondiabetic hypertensive patients. A reanalysis of the HOT study. Arq Bras Cardiol. 2001;77:132-137.

57 Shea S, Misra D, Ehrlich MH, et al. Predisposing factors for severe, uncontrolled hypertension in an inner-city minority population. N Engl J Med. 1992;327:776-781.

58 Nobre F, Chauchar F, Viana JM, et al. Evaluation of the medical care of patients with hypertension in an emergency department and in ambulatory hypertension unit. Arq Bras Cardiol. 2002;78:159-161.

59 Ooi WL, Budner NS, Cohen H, et al. Impact of race on treatment response and cardiovascular disease among hypertensives. Hypertension. 1989;14:227-234.

60 Walker WG, Neaton JD, Cutler JA, et al. Renal function change in hypertensive members of the Multiple Risk Factor Intervention Trial. Racial and treatment effects. The MRFIT Research Group. JAMA. 1992;268:3085-3091. 